\title{
The estimation methods of occupational skills transferability
}

\author{
Kritkorn Nawakitphaitoon ${ }^{1} \cdot$ Russell Ormiston $^{2}$
}

Accepted: 20 September 2016 / Published online: 20 October 2016

(C) The Author(s) 2016. This article is available at SpringerLink with Open Access.

\begin{abstract}
This paper compares two estimation methods of occupational skills transferability, both theoretically and empirically. The first method is based on Shaw's (1984) study, and the second one is based on Ormiston's (2014) study. The main difference between these two methods is that Shaw's skills transferability is a "market" approach. It is estimated based on an actual occupational change. On the other hand, Ormiston's skills transferability is a "skills" approach estimated based on the knowledge, skills, and abilities (KSAs) shared across occupations. Although these two approaches produce very different estimates of occupational skills transferability, both estimates significantly explain the earnings losses of displaced workers. In particular, the displaced workers who find jobs in occupations more similar to their previous jobs, as measured by occupational skills transferability, on average, suffer smaller earnings losses than those who find less similar jobs.
\end{abstract}

Keywords Occupational human capital · Skills transferability $\cdot$ Earnings losses

JEL classification $\mathrm{J} 31 \cdot \mathrm{J} 62 \cdot \mathrm{J} 63$

Kritkorn Nawakitphaitoon

nawakitp@ruc.edu.cn, kengha_di@hotmail.com

Russell Ormiston

rormisto@allegheny.edu

1 School of Labor and Human Resources, Renmin University of China, Beijing, China

2 Department of Economics, Allegheny College, Meadville, PA, USA

\section{Die Methoden zur Einschätzung der Übertragbarkeit beruflicher Kompetenzen}

Zusammenfassung Dieser Beitrag vergleicht zwei Methoden zur Einschätzung der Übertragbarkeit beruflicher Kompetenzen sowohl in theoretischer als auch empirischer Hinsicht. Die erste Methode basiert auf der Studie von Shaw (1984), die zweite auf der Studie von Ormiston (2014). Der Hauptunterschied zwischen den beiden dort verwendeten Methoden liegt darin, dass die Übertragbarkeit der Kompetenzen nach Shaw ein „marktorientierter“ Ansatz ist. Die Bewertung erfolgt anhand eines tatsächlichen Berufswechsels. Die Übertragbarkeit der Kompetenzen nach Ormiston hingegen ist ein ,kompetenzorientierter“ Ansatz, der auf der Grundlage von Wissen, Kompetenzen und Fähigkeiten über Beschäftigungen hinweg bewertet wird.

Obwohl diese beiden Ansätze sehr verschiedene Einschätzungen der Übertragbarkeit beruflicher Kompetenzen liefern, erklären beide Methoden wirkungsvoll die Einkommensverluste der freigesetzten Arbeitskräfte. Insbesondere haben freigesetzte Arbeitskräfte, die Beschäftigungen finden, die, gemessen an der Übertragbarkeit beruflicher Kompetenzen, ihren früheren Beschäftigungen stärker ähneln, im Durchschnitt geringere Einkommensverluste als diejenigen, die weniger ähnliche Beschäftigungen finden.

\section{Introduction}

The original theoretical underpinnings of the human capital model advocated two types of worker skills: "general" human capital that could be utilized among all employers and "firm-specific" skills only applicable at a single employer (Becker 1964; Mincer 1974). Subsequent research, 
however, has advanced a considerably more nuanced interpretation of human capital. While the original model treated the portability of worker skills between employers as an all-or-nothing proposition, Shaw (1984) established that skill transferability between jobs is instead proportional on the basis of their shared occupational demands, giving rise to the concept of "occupation-specific" human capital (OSHC). To verify this proposed component of the human capital model, Shaw (1984) empirically demonstrated that occupation-specific human capital was a superior predictor of worker earnings than general experience. Kambourov and Manovskii (2009) extended these findings, with estimated returns on occupational tenure substantially outpacing returns on industry- and firm-specific tenure. Taken together, these two studies indicate that occupation-specific human capital represents the predominant human capital influence on individual workers' earnings.

Given the significance of the conclusion, a growing research agenda has confirmed and expanded upon the predictive power of occupational specificity in the determination of worker earnings (e. g., Ingram and Neumann 2006; Poletaev and Robinson 2008; Gathmann and Schönberg 2010; Geel et al. 2011; Ormiston 2014; Nawakitphaitoon 2014; Nawakitphaitoon and Ormiston 2015). However, a lack of consensus over the best approach to estimate occupationspecific human capital represents a potential hindrance to the advancement of research. In Shaw's (1984) seminal work on occupation-specific human capital, she advanced the concept of "transferability," or the proportion of OSHC utilized in one profession that would be applicable in a second vocation. Two competing methods of estimating OSHC transferability have been developed to date: a "market" approach (Shaw 1984) and a "skills" approach (Ormiston 2014). As will be demonstrated in this study, there are vast differences - both theoretically and empirically - between these two methodologies, with considerable implications for how future research on OSHC is developed and interpreted.

The current paper, therefore, attempts to advance research on occupation-specific human capital by critically evaluating the strengths and weaknesses of these two methodologies - as offered by Shaw (1984) and Ormiston (2014) - and comparing them to alternative measures of occupational commonality discussed in the broader labor economics research. To start, this paper estimates Shaw's (1984) measure of transferability by analyzing occupational mobility in a data set derived from the March Current Population Survey (CPS). The Ormiston (2014) transferability metric is then estimated using O*NET - the U.S. Department of Labor's occupational database - to compute the ratio of shared, standardized knowledge, skill and ability categories across occupations. Finally, to demonstrate how these two approaches produce disparate outcomes, both transferability measures are linked to post-displacement earnings among displaced workers as identified in the 2004-2010 Displaced Worker Survey (DWS).

This paper is structured as follows. The next section describes the estimation of occupational skills transferability applying Shaw's (1984) and Ormiston's (2014) approaches. Sect. 3 discusses the theoretical strengths and weaknesses of these two approaches. Sect. 4 describes the data and empirical estimation of earnings losses of displaced workers. Sect. 5 presents the estimation results and empirical comparison of these two approaches, and the last section concludes and discusses some of the implications for future research.

\section{The estimation of occupational skills transferability}

As described above, the primary purpose of this paper is to compare the two existing methods of estimating occupational skill transferability: Shaw (1984) and Ormiston (2014). These two methodologies take on divergent approaches. Shaw (1984) uses a "market" approach, estimating skills transferability via occupational mobility patterns, arguing that there will be greater occupational mobility between jobs that have a higher rate of skills transferability. On the other hand, Ormiston (2014) measures occupational skills transferability using a "skills" approach based on a measure of commonality of knowledge, skills, and abilities (KSAs) across occupations. Each approach has strengths and weaknesses which will be discussed below.

\subsection{Shaw's skills transferability method (market approach)}

Shaw (1984) defined "occupational investment" as the "accumulation of skills an individual acquires to perform work within an 'occupation"' (p. 320). Distinguishing occupation-specific human capital from firm-specific human capital, Shaw identified that the economic return to the stock of the former was not completely foregone after an occupational change; instead, the return depended on the transferability of skills from one occupation to the next. Defining OSHC transferability, Shaw established that "as a change from occupation $i$ to occupation $j$ is made, an individual will transfer $t_{i j}$ percent of his skills from occupation $i$ to occupation $j, "$ (p. 321). Empirically, this definition of transferability implies the following:

$t_{i j}=\frac{O S H C_{i} \cap O S H C_{j}}{O S H C_{i}}$

In this interpretation of OSHC transferability $\left(\mathrm{t}_{i j}\right)$, the numerator represents the amount of overlapping occupational 
skills required across both occupations while the denominator denotes the amount of occupational skills required of one's former occupation $i$.

Shaw (1984) estimated OSHC transferability through observed labor market outcomes: cross-occupational switching rates as derived from a retrospective question in the 1970 Census. By taking a "market" approach, the study argued that the probability of occupational change increased with higher transferability of skills across vocations. However, the difficulty of directly using occupational switching incidence as an approximation of OSHC transferability is that it likely picks up other determinants of mobility that are unrelated to human capital. Shaw (1984) thus proposed estimating the "distance" between occupation $i$ and occupation $j, D_{i j}$, as follows:

$$
\begin{aligned}
D_{i j}= & \sum_{k=1}^{J}\left|P_{i k}-P_{j k}\right|=\left(P_{i j}+P_{j i}\right)-\left(P_{i i}+P_{j j}\right)+ \\
& \sum_{k=1}^{J}\left|P_{i k}-P_{j k}\right|
\end{aligned}
$$

where $P_{i k}$ represents the probability of an occupational switch between occupation $i$ and occupation $k, P_{\mathrm{ii}}$ and $P_{\mathrm{jj}}$ respectively denote the probability of moving across more detailed occupations within aggregate occupations $i$ and $j$, and $J$ is the set of all occupations. The advantage of using the above distance formula is that the last term incorporates rates of occupational movement between $i$ and $j$ and other occupational categories. If incumbents in occupations $i$ and $j$ move to a separate occupation $k$ at similar rates, this smaller distance implies greater commonality of skill portfolios between occupations $i$ and $j$, or higher rates of OSHC transferability. Given the inverse relationship between distance of assumed transferability rates - and the fact that $D_{i j}$ takes on a range of zero to two instead of representing a proportion - Shaw (1984) scaled her measure as follows:

$d_{i j}=1-\left(D_{i j} / 2\right)$

Note that $d_{i j}$ is a symmetric matrix, $d_{i j}=d_{j i}$; the direction of occupational movement does not matter. The skills transferability from occupation $i$ to $j$ is equal to that from occupation $j$ to $i$, and $d_{i j}$ measures the average transferability between these two directions of movement.

In this paper, Shaw's occupational skills transferability is estimated at the two-digit level of the 2000 U.S. census occupational classification system encompassing 22 voca- tional categories. ${ }^{1}$ To estimate occupational skill transferability applying Shaw's method, one of the requirements for the dataset is that it has to be a large sample. Thus, this paper uses the 2003-2006 March CPS, as it represents a random sample of over 60,000 households every month, weighted to be representative of the U.S. population. This dataset provides the current and "one year ago" occupations of respondents, 18 years or older and not in school. Note that the short interval length of occupational switches could also produce high vocational retention rates (Shaw 1984). Aggregating the four March CPS survey years, this paper has data for 514,134 individuals who are between 18 and 65 years old. Deleting individuals who do not have information on occupations at the current year and/or one year ago, the final sample size is 434,902 . Using this data, this study derives the $22 \times 22$ occupational skills transferability matrix based on two-digit U.S. census occupation code.

\subsection{Ormiston's skills transferability method (skills approach)}

While Shaw (1984) demonstrated that occupation-specific human capital was a far more powerful predictor of worker earnings than general human capital, subsequent research on OSHC remained largely dormant until a surge of interest in the late 2000s (e.g., Zangelidis 2008; Kambourov and Manovskii 2009; Sullivan 2010). However, these papers treated all vocational changes as identical - classifying workers as occupational switchers or occupational stayers - thereby ignoring the "distance" between occupations that is central to Shaw's original premise regarding skill transferability. Other papers - such as Poletaev and Robinson (2008) - examined the commonality of occupational skill portfolios; however none explicitly linked their approaches to Shaw's original definition of OSHC transferability.

This methodological disconnect represented the foundation of Ormiston (2014), which to date is the only known study that offers an alternative method of estimating OSHC transferability. Instead of analyzing occupational switching incidence, this study employs a "skills" approach by explicitly estimating the proportion of knowledge, skills and abilities (KSAs) utilized in occupation $i$ that can also be applied in occupation $j$. To estimate this proportion, Ormiston (2014) used data from O*NET - the U.S. Department of Labor's occupational database - to examine the commonality of occupations across 120 standardized knowledge, skill

\footnotetext{
1 While it using three-digit occupational codes would be preferable, the lack of vocational mobility between many of these more-detailed occupational codes - a 160,000-cell matrix - led this approach to predominantly estimate zero transferability for many occupational pairs.
} 
Table 1 Knowledge scores using to calculate occupational skills transferability

\begin{tabular}{llll}
\hline Occupation & \multicolumn{2}{l}{ Score of three selected knowledge dimensions } & \\
& Administration and management & Engineering and technology & Sales and marketing \\
\hline HR manager & 19.68 & 1.03 & 5.99 \\
Industrial engineer & 16.01 & 23.50 & 9.76 \\
\hline
\end{tabular}

Source: O*NET dataset

and ability dimensions. ${ }^{2} \mathrm{O} * \mathrm{NET}$ examines each occupation and measures each component on the level (0-7 scale) of proficiency needed to function within the profession and the importance (1-5 scale) of each component to the occupation; multiplying these values together generates a comprehensive score, $S_{i m}$, for each component $m$ of occupation $i$. To estimate the transferability of OSHC from occupation $i$ to occupation $j$, Ormiston (2014) proposes the following:

$t_{i j}=\frac{1}{N} \sum_{n=1}^{N} \frac{\sum_{m=1}^{M} \min \left(S_{i m}, S_{j m}\right)}{\sum_{m=1}^{M} S_{i m}}$,

where $N$ represents the three KSA categories and $M$ denotes the number of components within each category (33 knowledge, 35 skills, 52 abilities). ${ }^{3}$ Consistent with the equation for transferability described above, the numerator represents the amount of shared points between occupations $i$ and $j$ summed across $m$ components while the denominator represents the total number of points employed in occupation $i$ summed across $m$ components. The subsequent quotient represents the transferability rate for each $n$ category. Since each KSA category includes an uneven number of components, Ormiston (2014) estimates the overall OSHC transferability rate by taking the arithmetic mean of the three category rates. Following this method, this study first estimates the skills transferability across 500 occupations based on the three-digit occupational codes and then aggregate these transferability estimates into 22 occupations in the two-digit level by taking the arithmetic mean within each two-digit category for the comparison with Shaw's skills transferability. As a result, this study derives the $22 \times$

\footnotetext{
2 The use of knowledge, skill and abilities categories are preferred over task-focused measures of occupational comparability as utilized by Gathmann and Schönberg (2010). In particular, Gathmann and Schönberg (2010) build metrics based on common tasks; however, this approach lumps all job tasks - across all occupations - into 19 very general tasks. Thus, it is overly simplistic and ignores the distinctions caused by differences in specific knowledge or skills categories - such as the requirements of sufficient medical knowledge among nurses and physicians - resulting in biased estimates of OSHC transferability.

${ }^{3}$ Examples of knowledge components include administration and management, engineering and technology, and sales and marketing; examples of skill components include complex problem solving, mathematics, and negotiation; examples of ability components include control precision, fluency of ideas, and memorization. For a complete list of KSA components, see Table 10 in Nawakitphaitoon (2014).
}

22 occupational skills transferability matrix based on twodigit U.S. census code, representing the estimated proportion of occupational human capital transferability.

Table 1 provides an abbreviated example of the Ormiston (2014) approach, using two occupations, HR manager (i) and industrial engineer $(j)$, and three knowledge components $(m)$. The data indicate that HR managers can apply only 16.01 of their 19.68 points utilized in their current profession into a new role as an industrial engineer. However, given differences in occupational skill portfolios, HR managers could apply all of their required knowledge in engineering and technology (1.03 points) and sales and marketing (5.99) in a new position as an industrial engineer. Summing the amount of shared points between occupations $i$ and $j$ (23.03) and dividing by the total points employed in occupation $i$ (26.70) results in an estimated transferability rate of $86.30 \%\left(t_{i j}=0.863\right)$.

The Ormiston (2014) method of calculating OSHC transferability is inherently dependent on the choice of the original occupation $i$ and the destination occupation $j$; in other words $t_{i j}$ does not necessarily equal $t_{j i}$. The derivation of $t_{j i}$ from the above example would use the same numerator - the shared point total across occupations (23.03) - but the denominator would represent the total points (49.27) employed by incumbents in occupation $j$, the industrial engineer. Therefore, the estimate of $t_{j i}$ suggests that industrial engineers can only transfer $46.70 \%\left(t_{j i}=0.467\right)$. The asymmetry of the resulting transferability matrix, $T_{i j}$, is an expected outcome; higher transferability rates should accompany worker movement from entry-level jobs to more advanced positions. In contrast, occupational switches from complex to simple jobs results in the obsolescence of previously applicable skills, reflecting lower transferability rates.

\section{Theoretical comparison of shaw's and ormiston's estimations}

With numerous recent studies confirming the importance of the occupational dimension of workers' human capital, future research on OSHC requires a closer examination of how the concept is defined and measured. As the formative paper on occupation-specific human capital, Shaw's (1984) advancement of OSHC "transferability" represents one of the most versatile, applicable methods of understanding the 
overlap of skill portfolios across occupations. By condensing the analysis to a single metric - a proportion - Shaw's concept of transferability can be readily employed by researchers and policymakers to interpret how worker skills and job histories influence future earnings and occupational entry (Ormiston 2016).

While transferability rates may represent the foundation of research on occupation-specific human capital, the preceding sections demonstrate vast differences in the potential methods of their estimation. Empirically, the Shaw (1984) approach produces a symmetrical transferability matrix, $T_{i j}$, which distorts transferability estimates between secondary and primary labor markets. Beyond symmetry concerns, short-run occupational switching rates are significantly lower - as will demonstrated later in this paper than the cross-occupation transferability estimates produced by Ormiston (2014). While the symmetry issue can be quickly remedied by estimating different rates for $i j$ occupational changes separately from $j i$ vocational switches, the difference in estimated transferability rates introduces the potential for measurement error to undercut future research on occupation-specific human capital. Another limitation of Shaw's approach is that it must be driven by demand. If there is little demand for a given occupation, there will be little movement into it (i. e., low transferability), even from very similar occupations.

While the empirical differences between the methods employed by Shaw (1984) and Ormiston (2014) to estimate OSHC transferability are straightforward, the theoretical differences between these two methods - the "market" and "skills" approaches, respectively - are more complicated. By measuring transferability as the degree of comparability across occupational skill portfolios, the skills approach is more ideologically aligned with the tenets of the human capital model and the original definition of "transferability." Using this lens, researchers are able to detect skill complementarities between seemingly dissimilar vocations that influence occupational entry, productivity and worker earnings.

To demonstrate the capability of the "skills" approach, consider how experience as a media relations specialist serves as training for future employment as an economics professor. The development of one's communication skills - both written and oral - in the former occupation is a critical element of an individual's productivity and success in the latter profession; in other words, there is a clear nonzero degree of skill transferability between the two occupations. By examining a sufficient number of distinct KSA dimensions across occupations, this method will identify these similarities in vocational skill requirements and produce non-zero transferability estimates. ${ }^{4}$

Despite non-zero skill commonalities between media relations specialists and economics professors, meager occupational mobility rates between the two occupations both in the short- and long-run - would result in a market method estimating OSHC transferability to be practically zero. This outcome is unsurprising given a balkanized labor market wrought with formal and informal barriers that inhibit movement between professions without additional human capital investments. Conversely, substantial rates of occupational change between some vocations - especially within the secondary labor market - may have little to do with the commonality of applied skills, but rather lower barriers to occupational entry. Taken together, OSHC transferability estimates based on a market method are distorted by labor market institutions that considerably weaken the relationship between skill commonality and occupational movement.

While the skills approach of estimating transferability is more compatible with the principles of the human capital model, its applicability to labor market outcomes is conditional upon the development of appropriate weights across individual knowledge and skill categories (Lazear 2009; Geel et al. 2011). While two occupations may exhibit considerable commonality of occupational demands over a broad array of skills - such as media relations specialists and economics professors - this may be relatively unimportant compared to demonstrated proficiency within a specific knowledge or skill area that is most critical to vocational success and/or represents a barrier to occupational entry. Ormiston (2014) attempts to estimate these weights by multiplying the "level" and "importance" scores of each KSA component, but this approach produces largely arbitrary estimates that are complicated by low discriminant validity across O*NET categories (Harvey and Wilson 2010). This imperfection offers the potential for considerable refinement of the skills approach and the development of more exact skill weights; such an approach may incorporate some components of Shaw (1984) which, by its very design, is better at identifying barriers to occupational movement even

\footnotetext{
${ }_{4}$ Two studies measured the commonality of skill portfolios across occupations through the use of factor analysis (Ingram and Neumann 2006; Poletaev and Robinson 2008). This approach condensed occupational skill requirements provided by the Dictionary of Occupational Titles - the precursor to O*NET - into four distinct factors. While these papers were not attempting to estimate OSHC transferability rates, it is inappropriate to use factor analysis in their estimation. Knowledge categories, for instance, cannot conceivably be collapsed into a smaller number of dimensions. Doing so would not only deny the specificity of knowledge required of many vocations (e. g., accountants, electricians, professors) but may also conceal the very source of an occupation's distinctiveness; the result would be biased estimates of OSHC transferability.
} 
Table 2 The probability transition matrix (2003, 2004, 2005, and 2006 march cps)

\begin{tabular}{|c|c|c|c|c|c|c|c|c|c|c|}
\hline \multirow[t]{2}{*}{ Initial occupation (2000 code) } & \multicolumn{10}{|c|}{ Destination occupation (2000 code) } \\
\hline & (1) & (2) & (6) & (7) & (13) & $(15)$ & (16) & (17) & (19) & (20) \\
\hline Management (1) & 0.9648 & 0.0035 & 0.0007 & 0.0017 & 0.0019 & 0.0007 & 0.0073 & 0.0052 & 0.0019 & 0.0009 \\
\hline Business and finance (2) & 0.0083 & 0.9587 & 0.0008 & 0.0015 & 0.0009 & 0.0008 & 0.0069 & 0.0113 & 0.0009 & 0.0004 \\
\hline $\begin{array}{l}\text { Community and social service } \\
\text { (6) }\end{array}$ & 0.0037 & 0.0024 & 0.9526 & 0.0019 & 0.0018 & 0.0037 & 0.0040 & 0.0104 & 0.0014 & 0.0008 \\
\hline Legal occupations (7) & 0.0049 & 0.0022 & 0.0002 & 0.9733 & 0.0010 & 0.0002 & 0.0025 & 0.0079 & 0.0000 & 0.0000 \\
\hline Food preparation (13) & 0.0037 & 0.0014 & 0.0007 & 0.0002 & 0.9061 & 0.0075 & 0.0209 & 0.0173 & 0.0046 & 0.0013 \\
\hline Personal care and service (15) & 0.0027 & 0.0013 & 0.0019 & 0.0003 & 0.0104 & 0.9296 & 0.0124 & 0.0140 & 0.0016 & 0.0007 \\
\hline Sales (16) & 0.0060 & 0.0030 & 0.0008 & 0.0009 & 0.0090 & 0.0044 & 0.9331 & 0.0165 & 0.0024 & 0.0019 \\
\hline $\begin{array}{l}\text { Office and administrative } \\
\text { support (17) }\end{array}$ & 0.0042 & 0.0041 & 0.0009 & 0.0010 & 0.0048 & 0.0031 & 0.0107 & 0.9510 & 0.0013 & 0.0008 \\
\hline Construction (19) & 0.0039 & 0.0005 & 0.0002 & 0.0002 & 0.0037 & 0.0008 & 0.0045 & 0.0030 & 0.9509 & 0.0049 \\
\hline $\begin{array}{l}\text { Installation, maintenance, and } \\
\text { repair (20) }\end{array}$ & 0.0024 & 0.0003 & 0.0001 & 0.0001 & 0.0023 & 0.0008 & 0.0043 & 0.0030 & 0.0076 & 0.9592 \\
\hline
\end{tabular}

Source: $(2003,2004,2005$, and 2006 March CPS)

if the method is silent about the reason for such a barrier to exist.

As described above, the method of estimating the transferability of occupation-specific human capital between vocations is still in its nascent stages; its evolution is complicated by measurement issues and the presence of formal and informal barriers to occupational entry. However, a burgeoning research agenda on OSHC has demonstrated it to be the predominant human capital influence on worker earnings and, thus, worthy of additional study. At this point, researchers and policymakers interested in OSHC transferability have two options for its estimation: Shaw (1984) and Ormiston (2014). While the above section has outlined the primary theoretical conflicts between these two approaches, what follows will offer more detail on their empirical disparities and the implications that these differences have on the interpretation of OSHC's effect on worker earnings.

\section{Empirical estimation of earnings losses of displaced workers}

To examine the effect of transferability of occupational human capital skills on earnings losses following job displacement, this paper uses the 2004-2010 Displaced Workers Surveys (DWS). The Displaced Worker Survey was chosen in this analysis because it significantly attenuates endogeneity concerns, making it ideal to understand the effect of transferability on earnings. In particular, the decision to change jobs and occupations is incredibly complex in general. Fox (1994) highlights the endogeneity between earnings and jobs, as simultaneity exists in the relationship between earnings and most occupational changes. However, by using the DWS, this concern is minimized, as displaced workers represent involuntary job changers. Therefore, if one assumes that the decision to change jobs is already made - because the worker has no choice - the causal relationship is clearer, as displaced workers are expected to select the job with the highest earnings.

In addition, the DWS has been widely used in studies of displaced workers because of the comprehensiveness of its questions about the incidence and cost of job displacement. In particular, displaced workers in the DWS are identified based on a question in the CPS that asks, "During the last three calendar years, did you lose a job or leave one because: 1) the plant or company is closed or moved, 2) your position or shift is abolished, or 3) there is insufficient work?" If the answer from the respondent is "yes," they will be asked a series of questions regarding the lost job and current job (if they have been reemployed during the current survey). Also, it provides the information on pre- and post-displacement occupations, weekly earnings, and individual characteristics that we used in the regression analysis. The final sample consists of 6827 individuals.

To demonstrate the empirical implications of each approach, this paper applies these two approaches of occupational skills transferability to estimate the earnings losses associated with job displacement using a model first established in Nawakitphaitoon and Ormiston's (2015):

$\Delta \ln W_{\mathrm{i}}=\beta_{0}+\beta_{1}$ Transfer $_{\mathrm{i}, \mathrm{lc}}+\gamma^{\prime} X_{\mathrm{i}}+\varepsilon_{\mathrm{i}}$

$\Delta \ln W_{i}$ is the difference in the natural logarithm of real weekly earnings between pre- and post-displacement jobs for individual $i$, and negative values of this variable indicate larger earnings losses. Transfer ${ }_{i, l}$ is the measures of skills transferability between pre- and post-displacement occupations (i. e., from occupation $l$ to occupation $c$ ). $\beta_{1}$ is interpreted as the estimated effect of occupational transferability on earnings losses. If the transferability of occupational 
Table 3 The skills transferability matrix for 10 selected occupations (shaw's approach)

\begin{tabular}{lllllllllll}
\hline Initial occupation (2000 code) & \multicolumn{3}{l}{ Destination occupation (2000 code) } & & & & & \\
& $(1)$ & $(2)$ & $(6)$ & $(7)$ & $(13)$ & $(15)$ & $(16)$ & $(17)$ & $(19)$ & $(20)$ \\
\hline Management (1) & 1.000 & 0.038 & 0.031 & 0.024 & 0.035 & 0.033 & 0.039 & 0.037 & 0.025 & 0.022 \\
Business and finance (2) & 0.038 & 1.000 & 0.033 & 0.025 & 0.035 & 0.035 & 0.040 & 0.040 & 0.021 & 0.019 \\
Community and social service & 0.031 & 0.033 & 1.000 & 0.027 & 0.041 & 0.043 & 0.041 & 0.041 & 0.022 & 0.020 \\
(6) & & & & & & & & & \\
Legal occupations (7) & 0.024 & 0.025 & 0.027 & 1.000 & 0.024 & 0.023 & 0.025 & 0.026 & 0.014 & 0.011 \\
Food preparation (13) & 0.035 & 0.035 & 0.041 & 0.024 & 1.000 & 0.073 & 0.082 & 0.061 & 0.046 & 0.038 \\
Personal care and service (15) & 0.033 & 0.035 & 0.043 & 0.023 & 0.073 & 1.000 & 0.065 & 0.056 & 0.029 & 0.026 \\
Sales (16) & 0.039 & 0.040 & 0.041 & 0.025 & 0.082 & 0.065 & 1.000 & 0.063 & 0.036 & 0.032 \\
Office and administrative & 0.037 & 0.040 & 0.041 & 0.026 & 0.061 & 0.056 & 0.063 & 1.000 & 0.030 & 0.027 \\
support (17) & & & & & & & & & \\
Construction (19) & 0.025 & 0.021 & 0.022 & 0.014 & 0.046 & 0.029 & 0.036 & 0.030 & 1.000 & 0.044 \\
Installation, maintenance, and & 0.022 & 0.019 & 0.020 & 0.011 & 0.038 & 0.026 & 0.032 & 0.027 & 0.044 & 1.000 \\
repair (20) & & & & & & & & & \\
\hline
\end{tabular}

Source: (2003, 2004, 2005, and 2006 March CPS)

skills is important for determining the earnings losses, postdisplacement earnings should be higher for reemployed workers who find occupations more similar to their old jobs. This means we should expect $\beta_{1}$ to be positive. The degree to which a displaced worker could find a job similar to the previous occupation is also driven by various other dimensions, such as individual characteristics, the number of available vacancies in the year of job loss, and the possibility for geographical mobility. Therefore, this paper also includes variables denoting respondents' age, gender, marital status, labor market experience, level of education, race, years of tenure at the lost job, year dummies indicating when the job was lost during the three-year spell, one-digit occupation and industry dummies of the lost job, a geographical mobility dummy, and work history variables as the control variables $(X)$. To capture the labor market conditions that could affect the opportunities for displaced workers to find new jobs, this study also includes the measure of unemployment rate during the year of the survey across states and a dummy variable indicating the year of displacement.

OLS estimates in this analysis, however, may be subject to selection bias because the process of reemployment among the displaced workers is not random. The relationship between skills transferability and earnings losses in a sample of displaced workers who are reemployed at the survey date might be quite different from the relationship observed in the labor force as a whole. For example, those who were not reemployed may have had different unobserved characteristics affecting their earnings from those of reemployed group. If this is the case, the OLS method could produce biased and inconsistent estimates. To reduce the source of selection bias, in addition to using the full sample of all displaced workers, Nawakitphaitoon and Ormiston (2015) also use the sample of workers who were displaced at least one year before the survey date because those workers displaced in the most recent years are less likely to be reemployed and hence report their weekly earnings (For a more careful discussion about these analyzes, see Nawakitphaitoon and Ormiston (2015)).

\section{Estimation results}

\subsection{Summary statistics}

Consistent with the Shaw (1984) approach to estimating skill transferability, Table 2 presents the probability matrix of occupational movement $\left(P_{i j}\right)$ for 10 selected occupations in two-digit level calculated from the 2003-2006 March CPS. It suggests most individuals stay in the same occupation between "one year ago" and current year. For example, $96.0 \%$ of individuals who work in business and finance related occupations one year ago remain in the same occupation in the current year while only $0.08 \%$ becomes community and social service workers, and $0.69 \%$ becomes salespeople. The high retention rate would result in the small value of skills transferability, $d_{i j}$. Table 3 demonstrates the estimated Shaw's skills transferability matrix for 10 selected occupations in the two-digit level. Not surprisingly, the estimated skills transferability across two-digit occupations is relatively low and most of them are less than $10 \%$. For example, the skills transferability from business and finance workers to salespeople is 0.04 , suggesting that approximately $4.0 \%$ of occupational skills used by business and finance workers could be transferred to sales occupations; in comparison, these workers could transfer $2.1 \%$ of their skills into construction occupations. As mentioned above, the direction of the occupational movement is irrelevant for the skills transferability based on Shaw's method. 
Table 4 The skills transferability matrix for 10 selected occupations (ormiston's approach)

\begin{tabular}{lllllllllll}
\hline Initial Occupation (2000 code) & \multicolumn{3}{l}{ Destination Occupation (2000 code) } & & & & & \\
& $(1)$ & $(2)$ & $(6)$ & $(7)$ & $(13)$ & $(15)$ & $(16)$ & $(17)$ & $(19)$ & $(20)$ \\
\hline Management (1) & 1.000 & 0.589 & 0.589 & 0.556 & 0.365 & 0.423 & 0.529 & 0.408 & 0.291 & 0.372 \\
Business and finance (2) & 0.798 & 1.000 & 0.672 & 0.693 & 0.407 & 0.474 & 0.629 & 0.510 & 0.320 & 0.415 \\
Community and social service & 0.729 & 0.622 & 1.000 & 0.637 & 0.385 & 0.472 & 0.576 & 0.445 & 0.277 & 0.362 \\
(6) & & & & & & & & & \\
Legal occupations (7) & 0.759 & 0.691 & 0.689 & 1.000 & 0.386 & 0.458 & 0.600 & 0.508 & 0.301 & 0.394 \\
Food preparation (13) & 0.787 & 0.668 & 0.689 & 0.625 & 1.000 & 0.698 & 0.720 & 0.626 & 0.530 & 0.628 \\
Personal care and service (15) & 0.758 & 0.637 & 0.688 & 0.610 & 0.566 & 1.000 & 0.668 & 0.563 & 0.461 & 0.561 \\
Sales (16) & 0.786 & 0.693 & 0.691 & 0.663 & 0.484 & 0.552 & 1.000 & 0.555 & 0.374 & 0.478 \\
Office and administrative & 0.793 & 0.734 & 0.692 & 0.732 & 0.540 & 0.603 & 0.719 & 1.000 & 0.452 & 0.570 \\
support (17) & & & & & & & & & \\
Construction (19) & 0.585 & 0.476 & 0.433 & 0.437 & 0.479 & 0.507 & 0.500 & 0.461 & 1.000 & 0.740 \\
Installation, maintenance, and & 0.563 & 0.462 & 0.425 & 0.430 & 0.429 & 0.461 & 0.483 & 0.436 & 0.560 & 1.000 \\
repair (20) & & & & & & & & & \\
\hline
\end{tabular}

Source: O*NET dataset

Therefore, in this case the skills transferability from business and finance workers to salespeople is equal to that from salespeople to business and finance workers.

Table 4 presents Ormiston's skills transferability matrix for 10 selected occupations in the two-digit level. For example, the skills transferability from business and finance workers to salespeople is approximately 0.63, suggesting that $63.0 \%$ of KSAs used by business and finance workers would transfer to sales occupations. On the other hand, only $32.0 \%$ of KSAs could be transferred from business and finance professions to construction occupations. As opposed to Shaw's approach, the direction of occupational movement does matter for Ormiston's approach. While $52.9 \%$ of skills from management occupations could be transferred to sales occupations, $78.6 \%$ of skills from sales occupations could be transferred to management occupations.

The average skills transferability estimate using Shaw's method in this sample is approximately 0.075 with a standard deviation of 0.041 (see Table 5). The highest occupational skills transferability is between "food preparation workers" and "salespeople," which is around 0.082 while the lowest occupational skills transferability is between "legal occupations" and "Installation, maintenance, and repair occupations," which is 0.011 . The average skills transferability based on Ormiston's approach in this sample is approximately 0.577 with a standard deviation of 0.022 .

Table 5 Summary of occupational skills transferability

\begin{tabular}{llll}
\hline & \multicolumn{1}{l}{ Summary statistics of skills transferability (2-digit) } & Skills transferability \\
\hline $\begin{array}{l}\text { Ormiston's approach } \\
\text { Mean }\end{array}$ & From & & 0.577 \\
Standard Deviation & & & 0.022 \\
Most similar & & Management & 0.798 \\
& Business and financial operations & Management & 0.793 \\
Least similar & Office and administrative support & & 0.277 \\
& & Construction & 0.291 \\
Shaw's approach & Community and social service & Construction & \\
Mean & Management & & 0.075 \\
Standard Deviation & & & 0.041 \\
Most similar & & Sales and related occupations & 0.082 \\
& Food preparation & Personal care and service & 0.073 \\
Least similar & Food preparation & & Installation, maintenance, and repair \\
& & Construction & 0.011 \\
& Legal occupations & & 0.014 \\
\end{tabular}


The highest two-digit occupational skills transferability is from "business and finance related occupations" to "management," which is around 0.798 while the lowest occupational skills transferability is from "community and social service occupations" to "construction occupations," which is 0.277 .

As one can see from Tables 3 and 4, these two approaches yield very different magnitudes of skills transferability. For example, Shaw's approach suggests that the transferability from business and finance workers to salespeople is around 0.040 while Ormiston's approach indicates the transferability is around 0.629. The estimated correlation between Shaw's and Ormiston's approach is approximately 0.15 , statistically significant at a five-percent level, indicating a modestly positive correlation.

\subsection{Empirical comparison of shaw's and ormiston's skills transferability on earnings losses after job displacement}

This subsection discusses the empirical results comparing Shaw's and Ormiston's skills transferability at the two-digit level. Column (1) of Table 6 presents the effect of Ormiston's skills transferability on earnings losses. In particular, if the two-digit skills transferability increases by 10 percentage points, on average, it reduces real weekly earnings losses by $3.0 \%$, holding other factors fixed, and the estimated coefficient is statistically significant at the one-percent level. ${ }^{5}$ Column (2) presents the regression results based on Shaw's skills transferability. It shows that if the Shaw's skills transferability increases by 10 percentage points, on average, it reduces real weekly earnings losses by $1.0 \%$, holding other factors fixed, and it is also statistically significant at the one-percent level. Note that compared to Ormiston's skills transferability, the magnitude of Shaw's skills transferability is approximately three times smaller than that of Ormiston's coefficient. This could be explained by the argument in the preceding section that Shaw's skills transferability likely picks up other determinants of mobility that are unrelated to human capital, such as social and market demand factors.

The findings from these two approaches indicate a positive and strong relationship between the decline of earnings losses and occupational matches after job displacement. For example, consider the estimated earnings losses of two displaced workers from management occupation. Suppose that one finds a new job as a salesperson, and the other finds

\footnotetext{
5 This estimated coefficient is close to that at the three-digit level from Nawakitphaitoon and Ormiston's (2015) result suggesting a 10 percentage points increase in three-digit occupational skills transferability is associated with a $3.6 \%$ reduction in real weekly earnings, holding other factors fixed.
}

a job in the construction occupation. Ormiston's estimation of skills transferability from the management position to the sales position and construction occupation is equal to 0.529 and 0.291 , respectively. In comparison, Shaw's skills transferability from the management position to sales and construction occupation is 0.039 and 0.025 , respectively (see Tables 3 and 4). According to these estimates, if these two displaced workers remained in the same occupation in their new job (i.e., the occupational skills transferability is $100 \%$ ), their expected earnings losses would be 13.6 percentage points. On the other hand, the expected earnings losses due to the loss of skills transferability of the former management worker who reemployed as the salesperson was 16.3 percentage points based on Ormiston's method and 33.4 percentage points based on Shaw's method; the expected earnings loss of the worker who reemployed in the construction occupation was 38.3 percentage points based on Ormiston's method and 47.5 percentage points based on Shaw's method. Therefore, there is an approximately 17point difference in the expected earning loss due to the obsolescence of skills transferability for sales and a 9-point difference for construction between these two approaches.

As mentioned in the above section, to reduce the source of selection bias, this paper also analyzes the data restricting the sample to workers who were displaced at least one year before the survey date (i.e., the sample size is reduced to 4747). Columns (3) and (4) of Table 6 present the OLS results for this group of workers. Overall, the estimated transferability effect is very similar to those reported in Columns (1) and (2). For example, 10 percentage points increase in skills transferability, on average, reduces real weekly earnings losses by around $4.0 \%$ based on Ormiston's measure and $1.0 \%$ based on Shaw's measure, holding other factors fixed.

Beyond the effect of occupational skills transferability, Table 6 demonstrates other strong relationships between respondents' work history and subsequent earnings losses. For instance, staying in the same two-digit industry in the new job lowers earnings losses by 7.2 to 8.2 percentage points, all else equal. The statistically significant and negative coefficient of tenure at the lost job, -0.008 , indicates the importance of specialized skills that accumulate over time within a firm and are lost when changing jobs. The earnings losses of workers who were informed in advance about their job displacement were not statistically significant from those who were not informed in advance. The earnings losses of displaced workers who collected unemployment insurance benefits were significantly greater than those who did not collect the benefit by 4.4 percentage points, all else equal.

To sum up, these findings suggest that occupational skills are partially transferable across occupations as estimated based on Shaw's and Ormiston's approaches and contribute 
Table 6 Comparison of the return to shaw's and ormiston's skills transferability

\begin{tabular}{|c|c|c|c|c|}
\hline \multirow[t]{2}{*}{ Independent Variable } & \multicolumn{3}{|c|}{$\begin{array}{l}\text { Dependent Variable: Difference in log of real weekly earning } \\
(\$ 2006 ; \text { OLS) }\end{array}$} & \multirow[b]{2}{*}{ (4) } \\
\hline & (1) & (2) & (3) & \\
\hline \multirow[t]{2}{*}{ Ormiston transfer $* 100$} & 0.003 & & 0.004 & \\
\hline & $(9.25)$ & & $(8.32)$ & \\
\hline \multirow[t]{2}{*}{ Shaw transfer $* 100$} & & 0.001 & & 0.001 \\
\hline & & $(7.51)$ & & $(6.64)$ \\
\hline \multirow{2}{*}{ Same industry (2-digit) } & 0.072 & 0.082 & 0.077 & 0.087 \\
\hline & $(4.29)$ & $(4.85)$ & $(3.27)$ & (3.68) \\
\hline \multirow[t]{2}{*}{ Tenure at the lost job } & -0.008 & -0.008 & -0.009 & -0.010 \\
\hline & $(-4.88)$ & $(-4.96)$ & $(-5.73)$ & $(-5.83)$ \\
\hline \multirow[t]{2}{*}{ Notice of displacement } & 0.012 & 0.013 & -0.009 & -0.008 \\
\hline & $(0.68)$ & $(0.77)$ & $(-0.47)$ & $(-0.41)$ \\
\hline \multirow[t]{2}{*}{ Unemployment insurance } & -0.044 & -0.044 & -0.003 & -0.004 \\
\hline & $(-2.47)$ & $(-2.48)$ & $(-0.15)$ & $(-0.17)$ \\
\hline \multirow[t]{2}{*}{ Age } & 0.013 & 0.014 & 0.010 & 0.011 \\
\hline & $(2.31)$ & $(2.43)$ & $(1.50)$ & (1.64) \\
\hline \multirow[t]{2}{*}{ Age square } & 0.000 & 0.000 & 0.000 & 0.000 \\
\hline & $(-2.84)$ & $(-2.95)$ & $(-2.22)$ & $(-2.35)$ \\
\hline \multirow[t]{2}{*}{ Female } & -0.090 & -0.089 & -0.093 & -0.092 \\
\hline & $(-4.42)$ & $(-4.34)$ & $(-4.32)$ & $(-4.25)$ \\
\hline \multirow[t]{2}{*}{ Constant } & -0.208 & -0.014 & -0.088 & 0.120 \\
\hline & $(-1.61)$ & $(-0.11)$ & $(-0.58)$ & $(0.80)$ \\
\hline$N$ & 6827 & 6827 & 4727 & 4727 \\
\hline Adj. $\mathrm{R}^{2}$ & 0.085 & 0.082 & 0.096 & 0.091 \\
\hline
\end{tabular}

Note: $t$-statistics are in the parentheses. Not included independent variables are 10 major occupation dummies, 10 major industry dummies, marital status, US citizen dummy, union membership dummy, unemployment insurance benefit dummy, health insurance dummy, race dummies (i. e., black, white, Hispanic), dummy of move geographically, unemployment rate at year of survey across state, year of displacement, and 4 educational level

to the workers' earnings. In particular, the displaced workers who find jobs in occupations more similar to their previous jobs, as measured by occupational skills transferability, on average, suffer smaller earnings losses than those who find less similar jobs.

\section{Conclusion and implications for future research}

An emerging research agenda has consistently indicated that occupation-specific human capital represents the predominant human capital influence on individual workers' earnings. The potential labor market impact of OSHC transferability necessitates a theoretical and empirical comparison of the two published approaches to estimating OSHC transferability: the market-based method employed by Shaw (1984) and the skills-based approach advanced by Ormiston (2014). As demonstrated in this paper, these two approaches result in vastly different estimates of crossoccupational skill transferability, with the latter approach producing transferability estimates larger - by an order of magnitude, at minimum - than the former. These empirical differences, in turn, substantially influence the magnitude of the estimated earnings impact wrought by OSHC human capital portability across occupations. Future researchers are therefore cautioned that their choice of OSHC methodology has considerable implications on their findings.

In comparing the two existing methods of estimating OSHC transferability, the skills-based approach used by Ormiston (2014) better aligns with the tenets of the human capital model and, as demonstrated in Table 3 and 4, offers more reasonable estimates of cross-occupational skills transferability. However, this approach has a number of concerns. First, the KSA structure employed by O*NET offers discriminant validity concerns, as some components (e.g., strength) are potentially double- or tripledcounted while others represent more standalone components (e.g., economics knowledge). Second, the Ormiston (2014) method uses arbitrary skill weights - the product of component importance and level - that may or may not accurately reflect the applicability of skills across the vocational spectrum. Finally, formal and informal skilland knowledge-based labor market barriers complicate its applicability to studying labor market outcomes. For ex- 
ample, medical knowledge is of the utmost importance to physicians; without it, no amount of similarity from other KSA categories (e. g., interpersonal communication) means anything.

In contrast, the market-based approach proposed by Shaw (1984) relies entirely on occupational switching incidence. However, the presence of labor market barriers distorts the relationship between skill transferability and mobility, especially in the short-run. This paper, for instance, demonstrated that this approach yielded the highest rate of transferability between sales occupations and food preparation vocations. It is far more likely that this estimate is simply the result of higher turnover within the secondary labor market and, thus, represents an inadequate measure - by itself - of OSHC transferability.

As demonstrated in this paper, the development of the appropriate metrics to estimate the proportion of skills portable between jobs - OSHC transferability - remains in its nascent stages. While the skills-based approach employed by Ormiston (2014) appears preferable to a purely market-based method, this paper envisions that future efforts may be able to integrate the two approaches to produce more accurate estimates of cross-occupational skill weights. By studying occupational mobility, it may be possible to identify formal and informal skill-based labor market barriers indicative of higher or lower weights within a given occupational pair.

Acknowledgements We would like to thank Dale Belman, Todd Elder, Peter Berg, Mary Hamman, Christian Pfeifer, and two anonymous referees for offering helpful comments and suggestions. We also thank all seminar participants at Renmin University of China and Michigan State University. All remaining errors are ours.

Conflict of interest K. Nawakitphaitoon and R. Ormiston declare that they have no competing interest.

Open Access This article is distributed under the terms of the Creative Commons Attribution 4.0 International License (http:// creativecommons.org/licenses/by/4.0/), which permits unrestricted use, distribution, and reproduction in any medium, provided you give appropriate credit to the original author(s) and the source, provide a link to the Creative Commons license, and indicate if changes were made.

\section{References}

Becker, G.S.: Human capital. University of Chicago Press, Chicago (1964)

Fox, D.A.: Displacement and occupational mobility: evidence from the displaced worker surveys. East Econ J 20, 311-324 (1994)

Gathmann, C., Schönberg, U.: How general is human capital? A taskbased approach. J Labor Econ 28, 1-50 (2010)

Geel, R., Mure, J., Backes-Gellner, U.: Specificity of occupational training and occupational mobility: an empirical study based on Lazear's skill-weights approach. Educ Econ 19, 519-535 (2011)

Harvey, R.J., Wilson, M.A.: Discriminant validity concerns with the $\mathrm{O}^{*}$ NET holistic rating scales. Paper presented at the annual meeting of the Society for Industrial and Organizational Psychology, Atlanta. (2010)

Ingram, B.F., Neumann, G.R.: The returns to skill. Labour Econ 13, $35-59$ (2006)

Kambourov, G., Manovskii, I.: Occupational specificity of human capital. Int Econ Rev (Philadelphia) 50, 63-115 (2009)

Lazear, E.P.: Firm-specific human capital: a skill-weights approach. J Polit Econ 117, 914-940 (2009)

Mincer, J.: Schooling, experience, and earnings. Columbia University Press, New York (1974)

Nawakitphaitoon, K.: Occupational human capital and wages: the role of skills transferability across occupations. J Labor Res 35, 63-87 (2014)

Nawakitphaitoon, K., Ormiston, R.: Occupational human capital and earnings losses of displaced workers: does the similarity between pre- and post- displacement occupations matter? J Labour Mark Res 48, 57-73 (2015)

Ormiston, R.: Worker displacement and occupation-specific human capital. Work Occup 3, 350-384 (2014)

Ormiston, R.: Does high school employment develop marketable skills? J Labor Res 36, 53-68 (2016)

Poletaev, M., Robinson, C.: Human capital specificity: evidence from the dictionary of occupational titles and displaced worker surveys, 1984-2000. J Labor Econ 26, 387-420 (2008)

Shaw, K.: A formulation of the earnings function using the concept of occupational investment. J Hum Resour 19, 319-340 (1984)

Sullivan, P.: Empirical evidence on occupation and industry specific human capital. Labour Econ 17, 567-580 (2010)

Zangelidis, A.: Occupational and Industry Specificity of Human Capital in the British Labour Market. Scott J Polit Econ 55, 420-443 (2008)

Kritkorn Nawakitphaitoon is an assistant professor at School of Labor and Human Resources at Renmin University of China. He received his doctorate in Labor Relations and Human Resources, with major in Labor Economics from Michigan State University in 2012. His research interests are concentrated in the areas of labor economics, labor relations, and applied microeconomics. The main focus of his research is on the topic of occupational human capital.

Russell Ormiston is an assistant professor of economics at Allegheny College in Meadville, Pennsylvania, USA. His research interests include labor economics, sports economics and human resource management. 